clinical features, associated endocrine dysfunction, radiology, surgery and radiotherapy of pineal region tumours, with a specialized section on suprasellar germinomas or "ectopic pinealomas'.

It is a short, easily readable book with factual, up to date reviews. The standard of content of all the chapters is high, and the reviews of management of these rare tumours clear and well referenced. The analysis of ocular signs in this disease, with their neuro-anatomical correlation, is particularly detailed and informative. The editor of this volume, Dr Schmidek, considers the surgical management. He describes the methods available for biopsy or resection, including stereotactic approaches, and concludes that direct exploration should be reserved for patients with a high probability of having benign tumours and for those with progressive symptoms despite the presence of a functional shunt and following a full course of radiotherapy. Until the mortablity and morbidity of direct attack is reduced it will probably remain the view of the majority of neurosurgeons that exploration at the time of diagnosis is not in the patient's best interest.

The book is well illustrated, but contains a number of misprints, including one in a major subheading of the chapter on radiology (p. 79).

This volume deserves a place in all neurological libraries, but the price may deter the individual purchaser.

\section{Planning for a Family: an Atlas of Mucothermic Charts}

(Second edition). By John Marshall. Pp. 169, illustrated, paperback. Faber and Faber, London, Boston, 1979. £2.25.

This book is not written for doctors but for the general public, in particular those members of it who wish to plan their families without using the Pill or mechanical aids to contraception. It describes how one can avoid making love during the (most) fertile phase of the ovulation cycle. During the second half of the cycle this is done by restricting intercourse until the luteal phase is well established, as determined by a rise in the basal body temperature for 3 days that exceeds the temperature for the preceeding 6 days. Thus, in a woman with an ovulation cycle lasting 28 days, intercourse is 'safe' from day 17 to 28 . During the follicular phase the temperature chart cannot be used and to avoid conception the woman is advised to rely on a sensation of vaginal dryness (indicating lack of the copious lubricative mucus secreted by the cervix in the immediate pre-ovulatory phase). If she is uncertain about this sensation, and I suspect many women are, then she is advised to stop intercourse on the day determined by subtracting 18 from the number of days of the shortest cycle in the last 6 months (if the shortest cycle was 28 days long, intercourse would stop on day $28-18$ $=$ day 10). Thus, in the paradigm 28-day cycle, intercourse is considered 'safe' from day 17 through to day 10 of the next cycle.

This book does not concern itself with the reliability of the method nor does it reflect on what a palaver it turns sex into. The paradox that the shorter the luteal phase - and therefore when it lasts for less than 10 days the less the probability of conception - the greater the restriction on sex, is not commented on. Many charts are shown and interpreted; in one or two I suspect there was a conception with a very early spontaneous abortion. But the book is very clearly written and easy to understand and if you have patients to advise who are committed to 'natural' birth control, this is the book to recommend.
Quest for Excellence in Medical Education. A Personal Survey

By Sir George Pickering. Pp. 102. Oxford University Press, London - for Nuffield Provincial Hospital Trust, 1978. $£ 4.50$.

The former Regius Professor of Medicine at Oxford was commissioned by the Nuffield Provincial Hospitals Trust to undertake a survey of medical education in the U.K. This little volume is essentially a personal impression of the current situation, based on visits to a number of representative Universities and Medical Schools, Royal Colleges and Faculties, and several Postgraduate Medical Centres at district hospitals.

Sir George traces in outline the manner in which, from the Goodenough Report (1944), the pattern of medical education has changed. The undergraduate curriculum has been modified, compulsory resident house appointments have been introduced; and this development has paved the way to the establishment of a system of postgraduate education, which with the organization of specialist training and the introduction of vocational training for general practice is becoming fully comprehensive. Provision has also been made for continuing education throughout the Regions of the NHS. Sir George suggests that it may now be time for the GMC to accept responsibility for both undergraduate and postgraduate medical education, as recommended by the Merrison Report (1975).

Not everything has turned out for the best. The growth of larger undergraduate schools may or may not have been cost-beneficial: it has not necessarily led to the best pattern of instruction. The undergraduate curriculum has become increasingly overloaded and fragmented (there can be as many as $\mathbf{3 0}$ departments in the average medical school), and Sir George expresses concern at the increased use of examinations and particularly of papers relying on the MCQ technique. He sees this development as detrimental to proper medical education in the fullest sense. Rigidity of much specialist training is also criticized; and the advance of graduate clinical training is hampered by the conflict between education and service needs in training posts.

A short chapter is devoted to the special situation in London, where the 1974 re-organization of the NHS has accentuated the problems of the medical schools which do not have any specific Regional spheres of influence. No satisfactory solution has yet emerged to the problems of re-organizing medical education in London, and the author feels that the Todd Report proposals (1968) only served to confuse the situation and delay more appropriate reappraisals.

Book production is a costly business these days, but one ought perhaps to remark upon the high price of this slender volume.

\section{A Short Textbook of Haematology}

(Second edition). By R. B. Thompson. Pp. viii +465 , illustrated, paperback. Pitman Medical, London, 1979. f8.95.

Dr R. B. Thompson's book is now in its fifth edition indicating its continued popularity. The field of haematology continues to develop. There are few new diseases, but our knowledge of the old ones continues to develop in depth, and human ingenuity continues to devise newer and sometimes even better methods of management.

The 25 chapters cover the clinical disorders and where necessary include an account of the relevant physiology. There are many illustrations chosen with great care and add considerably to the value of the book. The quality of the paper, however, fails to do justice to the excellent radio. graphs. The style is lucid and easy to read. 
There is also a somewhat old-fashioned air about the material as if it was conceived before such vulgar objects as automated blood counters arrived on the scene. Blood counts are more often than not presented to the clinician as the output of automated counters, and the physician may have to consider how an abnormal MCH and/or MCV fits into the clinical picture. Unfortunately the clinician will not receive much help from this book. Alcoholism, an increasingly important cause of blood changes, is not mentioned nor is the common nutritional vitamin $B_{12}$-deficiency of Asian vegetarians. The diagnosis of polycythaemia rubra vera does not take into account arterial oxygen saturation, P50 values nor the relative merits of chlorambucil radiophosphorus or venesection and their relation to leukaemia. The differential diagnosis of iron deficiency omits the important anaemia of chronic disorders as in rheumatoid arthritis (but congenital transferrin deficiency is included).

Is the abnormal cell in glandular fever a mononuclear and not a lymphocyte and is 'fingers' the best way to record changes in the size of the spleen?

The book exceeds 460 pages and is approaching the middle division in length. One hopes the next edition of this deservedly successful book will rectify these and other omissions which indicate just a touch of middle-age spread.

\section{Treatment. A Handbook of Drug Therapy}

Edited by O. L. WAde, L. Beeley, V. W. M. Drury and P. A. Alesbury. Instalment 1. Kluwer Publishing, Brentford, Middlesex, 1979. First instalment, $£ 6.50$ with 2 binders at $£ 1.80$ each. Updating Service, annual subscription c. $£ 7.00$.

Those who are familiar with its 2 predecessors - 'Practice' and 'Laboratory' - in the series of loose-leaf manuals for general practitioners will need no explanation of the basic concept which this book follows. At present under review are the first 2 of the 5 instalments which will complete 'Treatment'; 2 binders will be needed to house the set. Ultimately, at approximately yearly intervals, replacement pages will be available where needed, so that each manual will be up-to-date. The manual is to be in 2 main sections, plus an appendix. The latter is to include a list of drug interactions, drug-induced diseases and drug prescribing in renal failure, pregnancy and lactation.

The first section is a list of drugs classified by their therapeutic action, together with their British proprietory names and approximate costings. It is impossible not to compare this part of the manual with the Monthly Index of Medical Specialities (MIMS) which every British GP gets once a month free of charge. Indeed, the editors of 'Treatment' acknowledge that that book is one of the 2 reference sources for the list of drugs they give. MIMS has the advantage of appearing monthly, not yearly, so that it is indeed up-to-date.

The second section is by far the most valuable. It is a description by symptoms of the diseases most commonly seen in general practice. The quality of the chapters varies considerably. A few are so terse and/or dogmatic that they tend to confuse more than they edify. Either the reader $\bar{\Phi}$

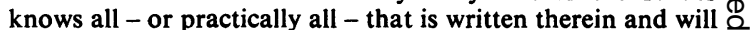
not need the book, or he will need much more detail about $c$. when and how to prescribe a particular drug in general $\Rightarrow$ practice and what are likely to be the side effects.

One criticism of detail: why is it recommended that somany drugs (for example, anti-rheumatics) should be taken every $6 \mathrm{hr}-$ which is how I interpret q6h. Only a grossly $\frac{\sigma}{\bar{C}}$ obsessional patient is going to follow that sort of regime. $\frac{D}{\partial}$ Most patients are likely to say to themselves: 'Every six $\mathbb{D}$ hours means 6 a.m., noon, 6 p.m. and midnight'. As they are usually asleep at $6 \mathrm{a} . \mathrm{m}$. and midnight they will only take $\omega$ their medication on the other 2 occasions! If by q6h the $\overrightarrow{0}$ authors mean 4 times a day (on rising, midday, late afternoon and before retiring) why not say so (qds)?

From the chapter list provided there does not appear to be any specific article on patient compliance, nor on poly- $\vec{\partial}$ pharmacy, both important in general practice. Because the book is loose-leaf it is not too late to have them included. 3 . Indeed, because the book appears mainly to be directed at or the trainee GP, a chapter on how to write a prescription, as $\mathrm{G}$ well as reference to the various drug regulations, would not be amiss, nor would something about repeat prescriptions.

\section{X-Ray Anatomy}

By George Simon and W. J. Hamilton. Pp. 343, illustrated. Butterworths, London, Boston, 1978. $£ 25.00$.

'Good God, how do you expect to become a radiologist if you don't know your anatomy?' Dr Simon's question will always be apt, and he has provided a book to help not only the aspiring radiologist, but also physicians and surgeons.

In 343 pages, divided into 8 chapters and 2 appendices, the book 'describes and illustrates elementary and advance $\overrightarrow{0}$ radiological anatomy' concisely and comprehensibly, withou going into detailed relationships. Surface anatomy, develo $\overline{\mathrm{q}}$ ment, common anatomical variants and changes with positiọn are dealt with in the text and the numerous clear illustrations.

The illustrations are of high quality but one or two arrows are misplaced and the captions of Fig 428 (a) and (b) have been switched.

In the first chapter there is a brief account of how X-rays $\mathbb{D}$ are produced and recorded, but it does not have enough detail for the radiologist so is presumably directed at others. $\vec{O}$

The skeleton and thorax together take up more than half 3 the book; this reflects the authors' interest. Less detail is $\supsetneq$ given to the abdomen; for example the liver, gall-bladder, spleen and pancreas are dealt with in two-and-a-half pages. These are shown better by ultrasound and CT scanning and transverse section anatomy has not been included in this book.

On the whole, this is a well written book and is recommended to trainee radiologists. They will have to supple- $\underline{3}$ ment it with more detail in some sections. More senior radiologists will find it useful in refreshing the memory, especially the accounts of development. Surgeons will need much more detail, but should find the illustrations helpful. 